Minuten lang damit gekocht, hierauf durchgeseihet und die schon entfärbte Fluissigkeit rasch eingedampft. Beim $\mathrm{Zu}$ satz von Salzsäure scheidet sich die Saure in bedeutender Menge aus und hat nach dem Auspressen zwischen Fliesspapier nur noch eine blassröthliche Farbe. Sie wird nun nach der Methode von Sch warz weiter gereinigt und in reichlicher Menge als ganz farblose Krystallnadeln olne Beimengung von Benzoesäure erhalten. Dadurch, dass man die Behandlung mit Kalkmilch unmiltelbar auf den Harn, statt auf die rohe Säure anwendet, kann man sich die Hippursäure in jeder beliebigen Menge verschaffen; man ist nicht jenen Unsicherheiten in dem Gelingen der Operation ausgesetzt, welche das Abdampfen des Harns fur sich mit sich bringt, und ist des langwierigen Abdampeens bei niedrigen Temperaturen iberhoben. Man kann sich auf diese Weise in 1 Tage so viel Hippursäure verschaffen, als bei der gewölinlichen Art zu arbeiten in 1 Woche. (Phil. Mag - Journ. of Sciences. - Pharm. Centralbl. 1847. No. 40.) $B$.

\title{
Ueber die qualitative Analyse des menschlichen Urins.
}

Mialhe hält die Untersuchung des Urins bei Kranken nicht für unwichtig, verwirft sie daher keineswegs. In Folgendem lehrt er, welcher Reagentien etc. man sich bedienen muss, um die Natur derselben zu erkennen.

1) Normale Färbung des Urins. Er ist klar und von einer mehr oder weniger dunkeln Bernsteinfarbe.

Färbung des Urins im pathologischen Zustande. Uebertrieben gefarbter Urin. Bei entzundlichen Krankheiten ist the Farbe desselben im Allgemeinen dunkler als gewöhnlich; manchmal röthlichgelb, mehr oder weniger rohbbraun, auch bis za einem gewissen Punct von derjenigen eigenThümlichen Färbung, wie alkalische Substanzen sie der firbenden Materie des Bluts mittheilen. Uebrigens kann auch die in dem Blute vorhandene organische Materie solche Erscheinungen darbieten. Der eben gelassene Urin ist zwar manchmal durch Ammoniakurat gefarbt; aber nicht dauernd, er verliert die Farbe im Kaltwerden, indem ein grosser Theil seiner salzigen Verbindungen niederfälth.

Fast ganz farblose Harne. In der Zuckerharnruhr ist der Urin am häufigsten farblos, und wenn sich diesem Zeichen eine merklich höhere Dichtigkeit zugeseltt, so steht man nicht an, ihn für diabetischen Harn zu erklären.

Doch ist dieses Urtheil nicht immer richlig. Mialhe 
hat einen Urin, welcher am Dichtigkeitsmesser 1030 angab, ganz frei von Zucker gefunden. Der diabetische Harn kann normalfarbig sein, wenn der Kranke Fleischspeisen und Bordeauxwein genossen hatte.

In der Albuminurie hat der Urin selten die gewöhnliche Farbe, und ist dieses Kennzeichen mit einer verminderten Dichligkeit mehrer Grade verbunden, so hat man die Reagentien auf Albumin anzuwenden.

Es giebt ein anderes organisches Uebel, welches unsre Nosologen nicht kannten, und oft mit der Harnruhr verwechselten, weil es mit dieser gemein hat, dass es eine grössere oder geringere Farblosigkeit des Urins bewirkt, nämlich die Polydipsie.

2) Geruch im normalen Zustande. Der Urin hat einen eigenthümlichen Geruch, der beim Erkalten meistens verschwindet, aber beim Erwärmen merklich wieder hervorkommt.

Geruch im pathologischen Zustande. Bei den Zuckerrubrkranken hat der Urin gewöhnlich einen Geruch, welchen man mit dem gewisser gährender Getränke verglichen hat; der aber in der That ein aroma sui generis ist, so dass man durch dieses den Urin eines diabetischen Kranken von andern Urinen unterscheiden kann.

3) Geschmack im normalen Zustande. Der normale Harn hat einen salzigbitterlichen unangenehmen Geschmack.

Geschmack im pathologischen Zustande. In der Zuckerharnruhr nimmt der Urin einen sehr deutlich süssen Geschmack an. Dieses Kennzeichen ist jedoch von ziemlich geringem Werth, denn es fehlt bei allen Zuckerruhrkranken, welche salzige Speisen zu sich nahmen, gewiss weil das Kochsalz die Eigenschaft hat, sich mit der Gluicose zu vereinigen und eine salzartige Verbindung zu bilden, in welcher das Kochsalz den Geschmack des Zuckers gänzlich bemäntelt.

4) Specifisches Gewicht im normalen Zustande. Die normale Dichtigkeit des menschlichen Harns ist zwischen 1013 und 1025 .

Gewicht im pathologischen Zustande. Ein Urin, welcher weniger als $1013 \mathrm{am}$ Dichtigkeitsmesser zeigt, kommt entweder von einer sehr mässig Jebenden Person, oder von einem grossen Wassertrinker, ferner, entweder von einem Albuminuristen oder von einem Polydipsinisten. Ein Urin von 1025 oder 1035 kindigt entweder die Gegenwart von Zucker oder von Albuminose, wie auch einen Ueberfluss von Harnstoff oder von Harnsäure an. 
Dieses sind die vornehmsten physikalischen Veränderungen, die der menschliche Urin gewönnlich darbietet.

Als wahres Caput mortuum der Verdauung und der Assimilation, oder um besser zu reden, aller dem grossen Act der Verdauung fremder Materialien, ist der Urin eine sehr complicirte Flüssigkeit, deren wahre Zusammensetzung man noch bei weitem nicht genau kennt. Uebrigens ist auch nicht zu leugnen, dass die chemischen Kennzeichen der mehrsten Bestandtheile dieser excrementalen Fluissigkeit heutiges Tages vollkommen bekannt sind, und diese wichtige Kenntniss hat schon miachtig zur Diagnostik und Behandlung einer grossen Anzahl von Krankheiten beigetragen.

Die folgenden Thatsachen werden dieser Verhandlung unfehlbar einigen Werth geben.

1) Harnstoff. In einigen unvollkommen bestimmten Fällen und namentlich in gewissen Abänderungen der Polydipsie, enthält der Urin nach P rout so viel Harnstoff, dass er schon ohne eingeengt $z u$ sein, auf reichlichen Zusalz von Salpetersäure, nach zwei Stunden, ein Nitrat des Harnstoffs absetzt.

Rührt der Urin nicht von einem Harnruhrkranken her, so hat Mialhe gefunden, dass er bei einer Dichligkeit von 1030 obige Erscheinung immer darbietet. In manchen Fällen trifft man wenig Harnstoff im Urin an, doch zeigt er sich stets, wenn man mit diesem wie folgt verfährt. Man raucht denselben bis zur Syrupsconsistenz $a b$, und versetzt ihn mit dem doppelten Gewicht an Salpetersäure. Letztere darf keine salpetrige Säure enthalten, da diese den Harnstoff entmischt. Kühlt man das Ganze in einer kaltmachenden Mischung ab, so setzt sich alsbald Harnstoffnitrat in Krystallen ab, manchmal erscheinen diese auch erst nach einigen Stunden.

2) Harnsäure. Glaubt man, dass ein Urin, welcher keinen rothen Absatz giebt, dennoch Harnsäure enthält, so muss man denselben 1) mit verschiedenen Quantitäten von Salpetersäure mischen und beobachten, ob er eine mehr oder weniger dichte Rosenfarbe annimmt, was ein Kennzeichen der Gegenwart der Harnsäure ist. 2) Muss man ein Probirglas mit dem zu untersuchenden Urin versehn, 30 Tropfen Salpetersäure hinzumischen und nach 12stündiger Einwirkung derselben die Flüssigkeit vom Bodensatz oder vielmehr von den sich an allen Seilen des. Glases zeigenden weissgrauen oder rothgrauen Krystallen abgiessen.

3) Albumin. Der Urin enthält ziemlich häufig Albu-

Arch, d. Pharm. CIl. Bds. 3. Hf. 
min, sei es, dass diese Substanz in Folge schlechter Beschaffenheit der Nieren entsteht, wie es die mehrsten Praktiker annehmen, oder dass die Erscheinung derselben durch eine Molecularveränderung des Albumins im Serum des Bluts, bei gesunden Nieren, wie man es vertheidigen darf, eintrifft. Die Sache verbalte sich übrigens wie sie wolle, so kann jeder Urin, der mit Salpetersäure behandelt, unmittelbar darauf ein weisses, in überschüssiger Säure unlösliches, nicht körniges Präcipitat giebt, als albuminhaltig angesehn werden.

4) Albuminose. Aus unsern Forschungen ist hervorgegangen, dass alle albuminhaltigen Substanzen während der Verdauung durch den doppelten Einfluss der Magensäure und des Pepsins zuletzt in ein besonderes Product iibergehen, welches weder durch Hitze, noch durch Säuren gefallt wird. Diesem hat man den Namen Albuminose gegeben; es wird als ein ausgeschiedener Theil der Fleischspeisen und albuminhaltigen Körper angesehen und ist bestandig im Urin vorhanden, wie man sich davon durch Merkurchlorid (Sublimat), sowie auch durch Gerbsäure leicht ubberzeugt, indem beide Reagentien die Albuminose nieder schlagen.

Oft ist das Verhältniss der Albuminose im Urin ziemlich schwach; dieses trifft aber bei Personen ein, deren Ernährung nicht sehr üppig war; oder dieses Verhältniss ist stark, wodurch die Dichtigkeil des Harns merklich vergrössert wird. Solcher Urin kommt von Personen, welche eine unmässige Diät führen oder auch von schwangeren Frauen: denn durch eine freiwillige Entmischung der Albuminose wird die Kysteine entstanden sein.

5) Blut. Wenn wirkliche Klutkügelchen in dem Urin vorhanden sind, so setzen sie sich gewöhnlich am Boden des Gefässes $a b$ und es ist dann leicht, die Natur derselben durch Hülfe des Mikroskops zu erkennen; findel sich aber der Farbstoff des Bluts im Urin aufgelöst, so muss man ersteren, nach Dumas, durch Gerinnung mittelst angebrachter Wärme abzusondern suchen, ferner die sich bildenden Flocken sammeln, und sie hierauf mit Alkohol und Schwefelsäure behandeln.

6) Sperma. Ist im Lrin spermatische Materie in einem merkbaren Verhältniss da, so kann über die Natur derselben kein Zweifel sein, durch die Eigenschaft nämlich, schon in der Kälte von der concentrirten Schwefelsäure aufgelöst und gelb gefärbt zu werden, während es bei der Essigsäure und Salpetersäure, wenn sie lösen sollen, der Hitze bedarf. Enthalt der Urin eine nur geringe Menge 
von Sperma, so muss man dieses auf einem Filter sammeln, und mittelst eines Mikroskops die Samenthierchen darin aufsuchen.

7) Färbende Materie der Galle. Nur durch Hiulfe der Salpetersäure lässt sich die Gegenwart der färbenden Materie der Galle im Urin beweisen. Hiezu giesst man die Säure vorsichtig am innern Rande des Glases hinunter, damit sich die Flüssigkeiten nicht vermischen; es entstehen dadurch drei verschiedene Lagen derselben, nämlich eine untere rosenfarbige, eine mittlere grünliche und eine obere braune.

8) Eiter. Man hat zwei verschiedene Hauptmittel, um die Gegenwart des Eiters im Urin zu erkennen, das Mikroskop und Ammoniak.

Der eiterhaltige Lrin ist trïbe und giebt einen weisslichen Bodensatz, in welchem man sich mittelst des Mikroskops von dem Vorhandensein der Eiterkügelchen überzeugt; denn diese unterscheiden sich von denen des Blutes durch grössere Durchsichtigkeit und geringere Regularität in ihrer Form.

Ammoniak dem Eiter hinzugefiugt, verursacht, dass daraus eine halbdurchsichtige gelbliche, in Fäden ziehbare Gallerte entsteht. Diese von Donné zuerst geJehrte Reaction giebt ein treffliches Mittel an die Hand, den Eiter vom Mucus zu unterscheiden; denn ohne Grund hat man geglaubt, dass dieser mit Ammoniak eine ähnliche Erscheinung darbieten könnte, was mit keinem andern Gemenge der Fall ist.

9) Zucker. Der Zucker im Urin ist ein sicheres Kennzeichen der Zuckerruhr oder der Glücosurie, und da diese Krankheit weit häufiger vorkommt als man glaubt, so sann man auf sichere Mittel, die Gliicose im Urin zu entdecken. Unter diesen nimmt das Polariskop Biot's, wie auch die Anwendung des Kalis, den ersten Platz ein. Aber ersteres ist $\mathrm{zu}$ theuer, auch die Handhabung desselben zu schwierig, um es in der gewöhnlichen Praxis zu gebrauchen. Das Kali ist zugänglicher. Die Anwendung desselben gründet sch auf die doppelte Erfahrung, dass ein Urin, welcher die Normalzusammensetzung hat, mit Kali erhitzt, keine sichtbare Färbung erleidet, während ein diabetischer Ilarn dann eine rothbraune Färbung zeigt, die desto dichter hervortritt, je stärker das Verbältniss der Glücose darin ist. Die Probe geschieht in einer unten verschlossenen Glasröhre, welche man mit dem Urin und einigen Tropfen Kaliauflösung, oder ein paar Bruchstiicken trocknen Kalis versieht, und dann bis zum Sieden des Inhalts erhitzt. 
Dieses Verfahren gestattet es, den Gang der Krankheit jeden Tag zu beobarhten, indem sich die Genesung hier umgekehrt wie die Färbung des Urins verhält, was also dem Praktiker crlaubt, seiner Heilungsmethode Schritt vor Schritt zu folgen und dem Kranken selbst die Besserung seines Uebels erkennen zu lassen; ein Umstand, den $\mathrm{M}$ i a l h e für einen unermesslichen Gewinn erachtet, da die Diagnostik dem Kranken und dem Arzt hierbei zugleich deutlich wird. (Journ. de Pharm. d'Anvers. Août 1847.)

$$
\text { du Mênil. }
$$

\section{Die Schädlichkeit der bleiernen Cisternen}

kann durch Zinkplatten gehoben werden. An bleierne Wasserröhren schraute man in gewissen Abständen ein Stückchen Zinkröhr, das man von Zeit zu Zeit abnimmt und reinigt. Ueber den Bleiboden lässt man von Hammerzink einen zweiten anbringen, welcher alle acht bis vierzehn Tage gereinigt werden muss. Das Zink wird jedes Atom Blei, das sich im Wasser auflöst, an sich zieben und festhalten. J. Rohinson glaubt dadurch die Gesundheit vieler Menschen zu erhalten. (The Athenaeum. - Voget's Notizen.)

$B$.

\section{Gussmarmor oder Mörtel der Alten.}

Aus angestellten Versuchen folgert 0 . 0 stermeier, dass der Mörtel der Alten aus einem Gemenge von Aetzkalk und kohlensaurem Kalk, nit Zusatz von zerkleinertem Kalkspath, bereitet worden sei. Zu seiner Herstellung räth der Verfasser, Kalkmilch mit Ireide bis zur Consistenz eines weichen Teiges zu mengen und ein gewisses Quantum gröblich gepulverten Kalksteins beizumischen. Eine glatte oberfläche soll mittelst eines Anstrichs von Milch erreicht werden. (Jahrb. für prakt. Pharm. 14. 4. 260.)

B.

\section{Beleuchtungsmittel zu optischen Zwecken.}

J. G. Childre n bedient sich bei den jetzt so beliebten Darstellungen der Dissolving views und des Physioskops einer Mischung von 1 Theil Kampher mit 8 Theilen Weingeist von $0,841 \mathrm{spec}$. Gew., deren Flamme mittelst eines Sauerstoffgebläses gegen einen Aetzlaalkcylinder getrieben wird. Das Licht besitzt die Intensität von 108-120 Wachskerzenflammen. (Phil.Magaz, and Transact. III. - Pharm, Centralbl. No. 28.) 